\title{
CONTRIBUIÇÃO AO ESTUdO DO POTENCIAL ALELOPÁTICO DE ESPÉCIES NATIVAS ${ }^{1}$
}

\author{
Fabiana Maraschin-Silva² e Maria Estefânia Alves Aqüila²
}

\begin{abstract}
RESUMO - Com o objetivo de conhecer o potencial alelopático de plantas nativas, foram avaliadas as espécies Erythroxylum argentinum, Luehea divaricata, Myrsine guianensis e Ocotea puberula. Realizaram-se bioensaios de germinação e crescimento em placas de Petri, usando alface como planta-alvo. Os aquênios e as plântulas foram tratados com extratos aquosos das folhas secas das espécies-teste, obtidos por maceração estática com água fria e quente. A germinação da alface foi levemente alterada por extratos de E. argentinum e L. divaricata. O crescimento da planta-alvo foi inibido pelos extratos das espécies testadas, ocorrendo reduções significativas das raízes. Esses resultados apontaram que as quatro espécies avaliadas apresentam potencial alelopático.
\end{abstract}

Palavras-chave: Alelopatia, Erythroxylum argentinum, Luehea divaricata, Myrsine guianensis e Ocotea puberula.

\section{CONTRIBUTION TO THE STUDY OF NATIVE SPECIES ALLELOPATHIC POTENTIAL}

\begin{abstract}
The species Erythroxylum argentinum, Luehea divaricata, Myrsine guianensis and Ocotea puberula were evaluated in order to investigate the allelopathic potential of native plants. Germination and growth bioassays were performed in Petri dishes, using lettuce as target plant. The achenes and seedlings were treated with aqueous extracts of the test species dried leaves obtained from static maceration with cold and hot water. Lettuce germination was slightly altered only by $\boldsymbol{E}$. argentinum and L. divaricata extracts. The target plant growth was inhibited by test species extracts, with significant root reductions. These results demonstrated that the four evaluated species present allelopathic potential.
\end{abstract}

Keywords: allelopathy, Erythroxylum argentinum, Luehea divaricata, Myrsine guianensis and Ocotea puberula.

\section{INTRODUÇÃO}

A alelopatia é um tipo de interação bioquímica entre vegetais, considerada uma forma de adaptação química defensiva das plantas, além de ser um fator de estresse ambiental para muitas espécies (LOVETT e RYUNTYU, 1992). Os aleloquímicos, substâncias químicas vegetais que atuam nessa interação, podem ter origem no metabolismo primário, mas em sua maioria são provenientes do metabolismo secundário, destacando-se as saponinas, os taninos e os flavonóides, que apresentam solubilidade em água (FERREIRA e AQÜILA, 2000; RODRIGUES, 2002).

Geralmente, a alelopatia resulta da ação de vários aleloquímicos em conjunto, sendo que essas misturas podem conter substâncias similares ou de naturezas químicas diversas (EINHELLIG, 1999). Na maioria dos casos, os aleloquímicos dessas misturas não são capazes de causar nenhum efeito sobre a planta-alvo quando sozinhos, uma vez que são liberados em pequenas quantidades em condições naturais (EINHELLIG, 1999; REIGOSA et al., 1999).

\footnotetext{
${ }^{1}$ Recebido em 21.01.2005 e aceito para publicação em 05.04.2006.

${ }^{2}$ Programa de Pós-Graduação em Botânica da Universidade Federal do Rio Grande do Sul, Av. Bento Gonçalves, 9500, Prédio 43433, s1 214 91509-900, Porto Alegre-RS. E-mail: <fabimaraschin@ terra.com.br>.
} 
Depois de liberados no ambiente através de várias rotas (WHITTAKER e FEENY, 1971; CHOU, 1986), os aleloquímicos podem causar diversos efeitos diretos e indiretos sobre as plantas. Os efeitos indiretos compreendem alterações nas propriedades e características nutricionais do solo e, também, nas populações e, ou, atividades de microrganismos, nematóides e insetos. Já os efeitos diretos incluem alterações no crescimento e metabolismo vegetal (RIZVI et al., 1992), englobando alterações em nívéis celular, fitormonal, fotossintético e respiratório, bem como modificações no funcionamento de membranas, na absorção de nutrientes e nas relações hídricas, entre outras (RICE, 1984; RIZVI et al., 1992).

A alelopatia é um fenômeno que influencia a sucessão vegetal primária e secundária, a estrutura e composição de comunidades vegetais, a dinâmica entre diferentes formações, a dominância de certas espécies vegetais - afetando a biodiversidade local - e a agricultura (CHOU, 1986; RIZVI etal.,1992; REIGOSA et al., 1999). Devido à importância que esse fenômeno apresenta em ecossistemas naturais ou manejados, muitos estudos já foram realizados sobre o tema, sendo que a grande maioria dos trabalhos envolve espécies de interesse econômico.

Apesar do aumento nas investigações sobre o potencial alelopático das espécies nativas ocorrido nas últimas décadas, o conhecimento atual ainda é considerado escasso (FERREIRA et al., 1992). Entre as espécies já estudadas, estão Mimosa bimucronata (JACOBI e FERREIRA, 1991), Baccharis trimera (FERREIRA et al., 1992), Achyrocline satureioides (AQÜILA et al., 1999), Ilex paraguariensis (AQÜILA, 2000), Mimosa caesalpiniifolia (PIÑA-RODRIGUES e LOPES, 2001), Myrciaria cuspidata (RODRIGUES, 2002), Caesalpinia pluviosa, Schizolobium parahyba, Mimosa artemisiana, Piptadenia gonoacantha, Clitoria fairchildiana e Erythrina speciosa (SOARES et al., 2002). Nesses trabalhos, os bioensaios laboratoriais têm sido amplamente utilizados em etapas iniciais, já que permitem estudar esse fenômeno isoladamente, ou seja, eliminando-se outros mecanismos de interferência que ocorrem na natureza.

O presente estudo teve como objetivo principal avaliar o potencial alelopático de Erythroxylum argentinum, Luehea divaricata, Myrsine guianensis e Ocotea puberula na germinação e crescimento inicial de Lactuca sativa, por meio de bioensaios laboratoriais, contribuindo, assim, para ampliar o conhecimento da alelopatia de espécies nativas.

\section{MATERIAL E MÉTODOS}

Foram usadas folhas adultas de E. argentinum, L. divaricata, $M$. guianensis e $O$. puberula, coletadas no Campus do Vale da Universidade Federal do Rio Grande do Sul, em Porto Alegre. Como espécie-alvo, empregou-se L. sativa (cultivar Branca Boston), cujos aquênios foram obtidos no comércio local. As folhas coletadas foram secadas durante 10 dias à temperatura ambiente $\left(25^{\circ} \mathrm{C}\right)$ e os extratos, preparados empregandose o método de maceração estática (SOARES e VIEIRA, 2000). Foi feita uma extração usando água quente, na qual as folhas inteiras foram imersas em água destilada, com temperatura inicial aproximada de $80^{\circ} \mathrm{C}$, nas concentrações de 2 e $4 \%$ (peso/volume), sendo mantidas na mesma água, resfriada naturalmente, até completar 24 h, não havendo controle nas condições de iluminação durante a extração (AQÜILA, 2000). Posteriormente, os extratos foram filtrados em funil forrado com gaze, seguindo-se uma centrifugação a $1.308 \mathrm{x} g$ por $10 \mathrm{~min}$, sendo os sobrenadantes utilizados diretamente nos bioensaios. Adicionalmente, foram preparados extratos a frio, nos quais as folhas inteiras foram imersas em água destilada fria na concentração de $10 \%$ (peso/ volume), sendo mantidas a $8^{\circ} \mathrm{C}$, no escuro, por $24 \mathrm{~h}$ (RUTHERFORD e POWRIE, 1993). Após esse período, o material foi filtrado e centrifugado, seguindo-se os mesmos procedimentos anteriormente, sendo o sobrenadante diluído para se obterem as soluções a 2 e $4 \%$, que foram, então, empregadas nos bioensaios.

Os extratos foram caracterizados quanto ao $\mathrm{pH}$ (aferido com pHmetro ou papel indicador), potencial osmótico (estimado pelo método de Chardakov SALISBURY e ROSS, 1992) e resíduo (RODRIGUES, 2002). Além disso, realizaram-se reações qualitativas de detecção de flavonóides, saponinas e taninos (FALKENBERG et al., 2003), nas quais foram feitos extratos à parte com folhas trituradas em água fervente por $15 \mathrm{~min}$.

O bioensaio de germinação foi conduzido em placas de Petri $(9 \mathrm{~cm}$ ) forradas com papel-filtro umedecido com os extratos ou com água destilada (controle). Foram semeados 20 aquênios de alface por placa, seguindo-se a incubação por $96 \mathrm{~h}$ em câmara 
de germinação a $25^{\circ} \mathrm{C}$, fotoperíodo de 12 h e irradiância de $45 \mathrm{mmol} \cdot \mathrm{m}^{-2} \cdot \mathrm{s}^{-1}$. O acompanhamento foi feito a cada $12 \mathrm{~h}$, sendo a curvatura geotrópica da raiz o critério de avaliação da germinação (FERREIRA e AQÜILA, 2000). Os aquênios que não germinaram foram submetidos ao teste do tetrazólio (BRASIL, 1992). Com os dados obtidos no bioensaio, calcularam-se a germinabilidade, o tempo médio de germinação e a entropia informacional da germinação (LABOURIAU, 1983).

No bioensaio de crescimento, foram colocados 10 aquênios de alface pré-germinados ( $1 \mathrm{~mm}$ de raiz) por placa de Petri $(9 \mathrm{~cm})$, forrada com papel-filtro umedecido com os extratos ou água destilada. As placas foram incubadas em câmara de germinação nas condições descritas anteriormente. Após seis dias, o comprimento do eixo hipocótilo-raiz das plântulas foi medido. Também foram feitos registros sobre a aparência das plântulas tratadas.

Foi utilizado um delineamento experimental em blocos casualizados com cinco tratamentos (um controle + quatro extratos). Cada tratamento teve seis repetições no bioensaio de germinação e 12 repetições no de crescimento, totalizando 120 aquênios por tratamento em cada bioensaio. Os dados foram submetidos a testes de hipóteses por meio da análise da variância $(\mathrm{a}=0,05)$, cujo resultado, independentemente do tipo de distribuição, foi submetido a testes de aleatorização e auto-reamostragem (bootstrap) (MANLY, 1991; PILLAR e ORLÓCI, 1996), utilizando-se o programa MULTIV versão 2.1.1 (PILLAR, 2001).

\section{RESULTADOS E DISCUSSÃO}

As curvas de germinação da alface ao longo de $96 \mathrm{~h}$ de bioensaio não foram afetadas pelos extratos das espécies testadas, quando comparadas com o controle (Figura 1). No entanto, foram constatadas diferenças significativas nas curvas de germinação entre tratamentos com extratos preparados a frio e a quente de L. divaricata e M. guianensis. Apesar de essas curvas serem semelhantes quanto à sua forma, a análise estatística detectou as diferenças nas germinabilidades parciais ao longo do bioensaio.

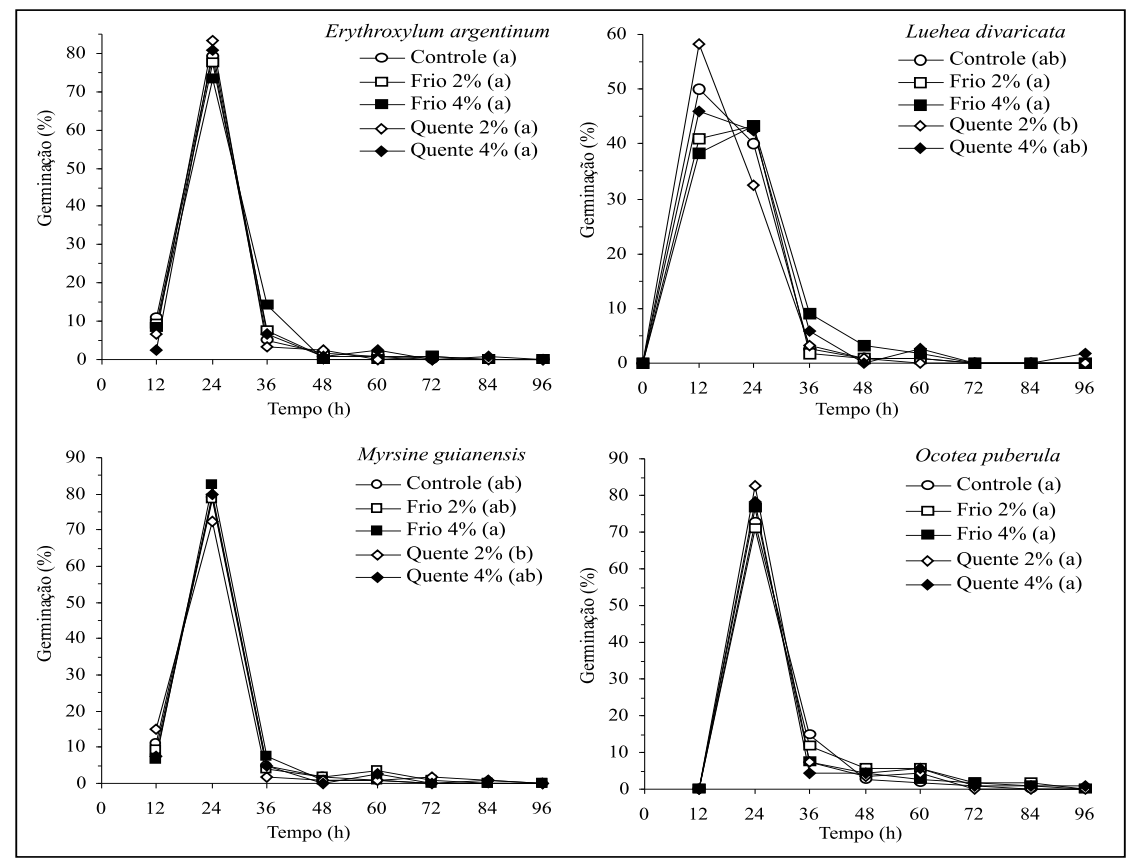

Figura 1 - Germinabilidade de aquênios de alface sob ação dos extratos foliares aquosos de E. argentinum, L. divaricata, $M$. guianensis e $O$. puberula. Dentro de cada bioensaio, curvas de germinabilidade com as mesmas letras não diferem entre si $(\mathrm{p} \leq 0,05)$.

Figure 1 - Lettuce germinability under the action of leaf aqueous extracts of E. argentinum, L. divaricata, M. guianensis and $O$. puberula. In each bioassay, germination curves with the same letters are not statistically different $(p \leq 0.05)$. 
Quadro 1 - Efeito de extratos foliares aquosos de espécies nativas nos índices de germinação de alface Table 1 - Effects of native species leaf aqueous extracts on lettuce germination indexes

\begin{tabular}{|c|c|c|c|c|}
\hline \multicolumn{2}{|c|}{ Bioensaio } & $\mathrm{G}(\%)$ & Tm (h) & E (bits) \\
\hline \multirow{5}{*}{ 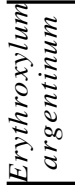 } & Controle & $97,50 \pm 2,739 a$ & $23,989 \pm 1,271 \mathrm{a}$ & $0,853 \pm 0,400 a$ \\
\hline & Frio $2 \%$ & $96,67 \pm 2,582 \mathrm{a}$ & $24,716 \pm 1,334 \mathrm{ab}$ & $0,875 \pm 0,374 a$ \\
\hline & Frio $4 \%$ & $96,67 \pm 4,082 \mathrm{a}$ & $25,159 \pm 1,321 \mathrm{ab}$ & $0,949 \pm 0,374 a$ \\
\hline & Quente $2 \%$ & $95,83 \pm 3,764 \mathrm{a}$ & $24,765 \pm 1,260 \mathrm{ab}$ & $0,651 \pm 0,383 a$ \\
\hline & Quente 4\% & $94,17 \pm 3,764 \mathrm{a}$ & $26,196 \pm 1,806 \mathrm{~b}$ & $0,661 \pm 0,248 \mathrm{a}$ \\
\hline \multirow{5}{*}{ 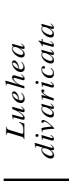 } & Controle & $94,17 \pm 7,360 \mathrm{ab}$ & $18,512 \pm 1,753 \mathrm{ab}$ & $1,162 \pm 0,214 a$ \\
\hline & Frio $2 \%$ & $87,50 \pm 6,892 a$ & $19,280 \pm 2,410 a b$ & $1,138 \pm 0,236 a$ \\
\hline & Frio 4\% & $95,83 \pm 3,764 b$ & $21,875 \pm 2,742 \mathrm{a}$ & $1,493 \pm 0,209 b$ \\
\hline & Quente 2\% & $95,00 \pm 3,162 b$ & $17,256 \pm 2,402 b$ & $1,103 \pm 0,266 a$ \\
\hline & Quente 4\% & $96,67 \pm 4,082 b$ & $20,017 \pm 2,868 \mathrm{ab}$ & $1,291 \pm 0,300 \mathrm{ab}$ \\
\hline \multirow{5}{*}{ 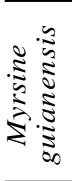 } & Controle & $97,50 \pm 2,739 \mathrm{ab}$ & $23,989 \pm 1,271 \mathrm{a}$ & $0,853 \pm 0,400 \mathrm{a}$ \\
\hline & Frio $2 \%$ & $97,50 \pm 2,739 a b$ & $25,432 \pm 2,175 \mathrm{a}$ & $0,918 \pm 0,274 a$ \\
\hline & Frio $4 \%$ & $98,33 \pm 2,582 a$ & $24,605 \pm 1,326 \mathrm{a}$ & $0,796 \pm 0,187 a$ \\
\hline & Quente $2 \%$ & $93,33 \pm 6,055 b$ & $24,293 \pm 1,992 \mathrm{a}$ & $0,972 \pm 0,221 \mathrm{a}$ \\
\hline & Quente 4\% & $95,83 \pm 3,764 \mathrm{ab}$ & $25,206 \pm 2,930 \mathrm{a}$ & $0,774 \pm 0,468 \mathrm{a}$ \\
\hline \multirow{5}{*}{ 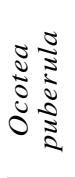 } & Controle & $93,33 \pm 5,164 \mathrm{a}$ & $28,109 \pm 1,431 \mathrm{a}$ & $0,897 \pm 0,135 \mathrm{a}$ \\
\hline & Frio $2 \%$ & $97,50 \pm 4,183 a$ & $30,819 \pm 5,045 \mathrm{a}$ & $1,064 \pm 0,577 \mathrm{a}$ \\
\hline & Frio $4 \%$ & $93,33 \pm 2,582 a$ & $28,386 \pm 2,852 \mathrm{a}$ & $0,889 \pm 0,374 \mathrm{a}$ \\
\hline & Quente 2\% & $97,50 \pm 4,183 a$ & $27,304 \pm 1,416 \mathrm{a}$ & $0,770 \pm 0,294 \mathrm{a}$ \\
\hline & Quente 4\% & $95,00 \pm 3,162 \mathrm{a}$ & $29,296 \pm 2,906 \mathrm{a}$ & $0,869 \pm 0,166 a$ \\
\hline
\end{tabular}

Média \pm desvio-padrão. G: germinabilidade total, Tm: tempo médio de germinação e E: entropia informacional da germinação. Letras iguais, na vertical dentro de cada bioensaio, não diferem estatisticamente ( $\mathrm{p} \leq 0,05)$.

Mean \pm standard deviation. G: total germination Tm: germination average time and E: germination entropy. Equal letters, in the vertical in each bioassay, don't differ statistically $(p \leq 0,05)$.

Ao final de $96 \mathrm{~h}$, a germinabilidade total dos aquênios de alface submetidos à ação dos extratos foliares das espécies estudadas não mostrou diferença significativa em relação ao tratamento-controle (Quadro 1). Entretanto, verificou-se aumento significativo no tempo médio de germinação da alface causado pelo extrato quente a $4 \%$ de $E$. argentinum, bem como incremento significativo na entropia de germinação dos aquênios submetidos ao extrato frio a $4 \%$ de L divaricata.

Comparando os efeitos causados por extratos frios e quentes, verificaram-se diferenças significativas nos três índices de germinação no bioensaio com $L$. divaricata (Quadro 1), principalmente entre tratamentos com concentrações distintas (2 e 4\%). No bioensaio com extratos de $M$. guianensis, também foi verificada uma diferença significativa na germinabilidade total entre os tratamentos com extrato frio a $4 \%$ e quente a $2 \%$.

Os bioensaios realizados com as quatro espécies testadas parecem reforçar a idéia de que a germinação não é o processo principal para as interações alelopáticas (INDERJIT e DAKSHINI, 1995), visto que foram constatadas alterações brandas em relação ao controle quanto ao processo de germinação dos aquênios tratados. Contudo, deve-se ressaltar que, apesar de as curvas de germinação da alface não terem sido alteradas pelos extratos de E. argentinum e L. divaricata, foram verificadas pequenas alterações nos índices de germinação, o que provavelmente tenha sido causado por pequenos picos de germinação ao final dos bioensaios, que acabaram tendo maior contribuição no cálculo desses índices.

O bioensaio com extratos de $L$. divaricata evidenciou que a germinação da alface começou antes da primeira avaliação, apresentando porcentuais bem elevados após as $12 \mathrm{~h}$ iniciais de incubação das placas. Provavelmente, possa ter ocorrido montagem mais rápida do experimento no dia anterior da primeira contagem, propiciando um tempo adicional para os aquênios ficarem em contato com os extratos ou com a água, totalizando cerca de $14 \mathrm{~h}$ na primeira avaliação. Contudo, no bioensaio com extratos de E. argentinum e M. guianensis, no qual o controle do tempo de montagem das placas e início da incubação foi mais rigoroso, também se observaou uma germinação dentro das $12 \mathrm{~h}$ iniciais. 
Considerando todos os bioensaios, a proporção de aquênios viáveis que não germinaram nas condições dos bioensaios variou de: $0,83-1,67 \%$ para o controle, $0-0,83 \%$ para o frio a $2 \%, 0-2,50 \%$ para o frio a $4 \%$, $0-0,83 \%$ para o quente a $2 \%$ e $0-0,83 \%$ para o quente a $4 \%$. Essas pequenas proporções encontradas corroboram com a idéia de um efeito brando sobre a germinação.

O crescimento da alface foi afetado pelos extratos testados, causando principalmente reduções no tamanho das raízes (Figura 2), em relação ao controle. Nos tratamentos com extratos de E. argentinum e $O$. puberula, foi verificada uma resposta mais acentuada nos extratos mais concentrados (4\%), sendo que nos tratamentos com extratos de $L$. divaricata e $M$. guianensis, isso não ocorreu. Comparando os efeitos dos extratos preparados a frio e a quente sobre as raízes, observaram-se diferenças significativas causadas por extratos de mesma concentração apenas nos bioensaios com E. argentinum e L. divaricata. Quanto ao tamanho dos hipocótilos, notaram-se aumentos significativos nos bioensaios com extratos de E. argentinum, $L$. divaricata e $M$. guianensis, além de uma redução no tratamento com extrato frio a $4 \%$ de $O$. puberula.

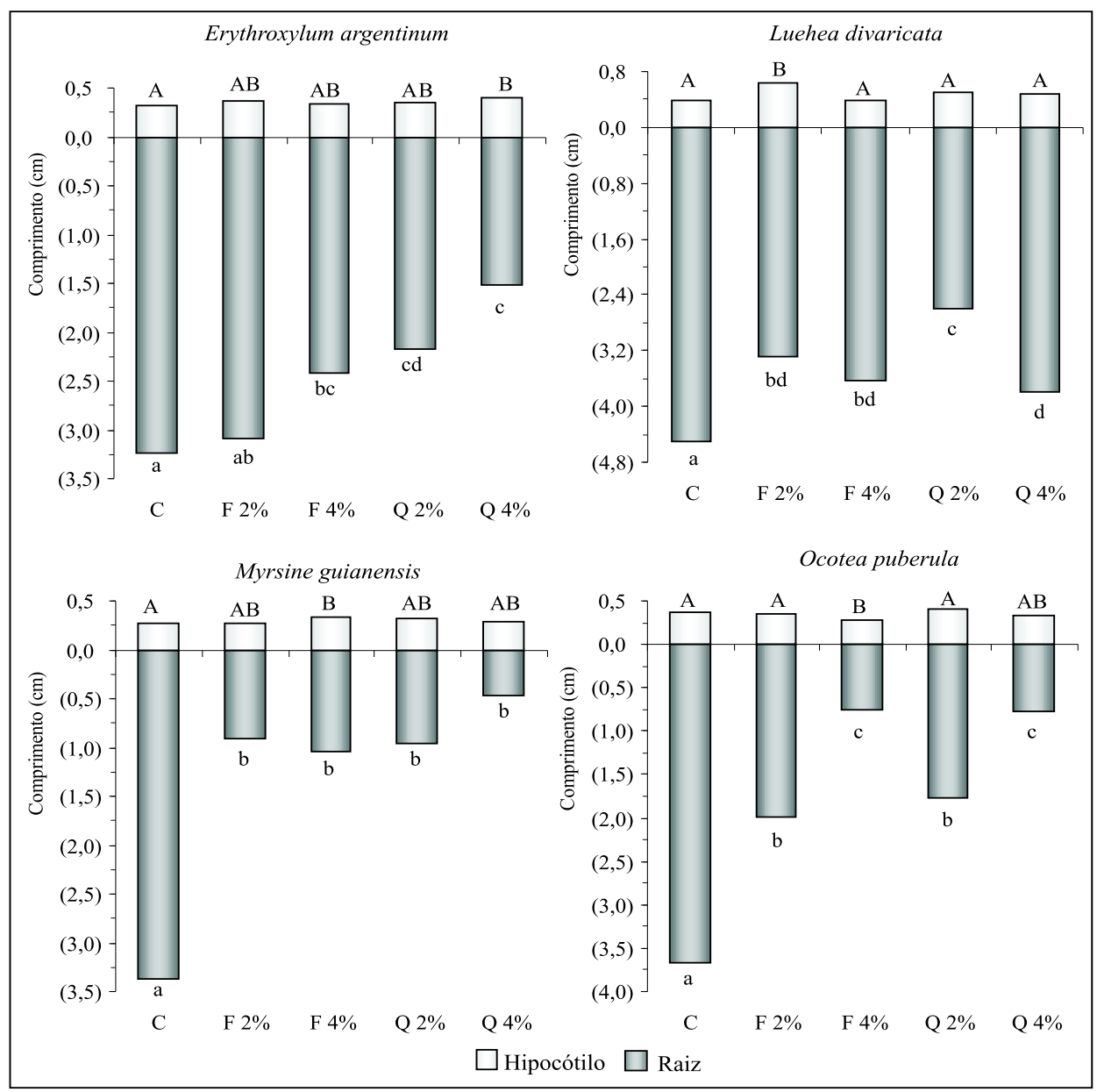

Figura 2 - Influência de extratos foliares aquosos de E. argentinum, L. divaricata, M. guianensis e O. puberula no crescimento inicial de plântulas de alface após $96 \mathrm{~h}$. Letras iguais na horizontal dentro, de cada bioensaio, não diferem entre si (p $\leq 0,05)$. C: controle, F 2\%: frio $2 \%$, F 4\%: frio 4\%, Q 2\%: quente $2 \%$ e Q 4\%: quente $4 \%$.

Figure 2 - Influence of leaf aqueous extracts of E. argentinum, L. divaricata, M. guianensis and O. puberula on lettuce initial growth after $96 \mathrm{~h}$. Same letters in the rows, in each bioassay, are not statistically different ( $p \leq 0.05)$. $C$ : control, $F 2 \%$ : cold $2 \%, F 4 \%$ : cold $4 \%, Q 2 \%$ : hot $2 \%$ and $Q 4 \%$ : hot $4 \%$. 
Relatos de outros estudos apontaram que o efeito comumente causado por extratos sobre o crescimento inicial é a redução no tamanho do eixo hipocótilo-raiz da planta-alvo (AQÜILA, 2000; RODRIGUES, 2002), sendo que, muitas vezes, a raiz tem contribuição maior nessa inibição. Segundo Chung et al. (2001), isso se deve ao contato mais íntimo entre as raízes e o papelfiltro tratado com aleloquímicos, usados em bioensaios com placas de Petri.

Os efeitos dos aleloquímicos, contudo, podem variar conforme o órgão da planta onde eles atuam (AQÜILA et al., 1999), sendo capazes de causar inibições em um órgão e pequenos incrementos em outro. A sensibilidade diferenciada constatada entre hipocótilos e raízes nos bioensaios com E. argentinum, $L$. divaricata e $M$. guianensis também pode ser um reflexo da fisiologia distinta desses órgãos.

Apesar de ser um resultado pouco freqüente, trabalhos anteriores já relataram estímulos no crescimento da alface, mas explicações detalhadas sobre esse efeito são escassas. Entre essas explicações pode-se sugerir uma interferência dos aleloquímicos nos fitormônios (AQÜILA et al., 1999).

Reigosa et al. (1999) relataram que os efeitos dos aleloquímicos nos diferentes processos fisiológicos de uma planta são dependentes da concentração, ou ao menos se espera que sejam, promovendo ativações em baixas concentrações e inibições em altas concentrações. Apesar disso, o bioensaio de L divaricata apresentou efeito de inibição mais acentuado nas raízes tratadas com extrato quente a $2 \%$ quando comparado com o quente a $4 \%$. Adicionalmente, os efeitos causados pelos extratos de $M$. guianensis sobre as raízes não diferiram entre si. Esses dois bioensaios, juntamente com o de $O$. puberula, indicaram também que nem sempre um extrato preparado com altas temperaturas, que promove maior extração, apresentará efeito mais acentuado em relação a um extrato preparado a frio. Nesse contexto, Reigosa et al. (1999) afirmaram que são comuns os efeitos "em serra" (inibições em baixas concentrações e promoções em altas concentrações), pois a quantificação de efeitos secundários reflete a soma não-linear de vários efeitos no nível primário. Os referidos autores ressaltaram ainda que cada processo fisiológico tem resposta diferente a certas doses de cada aleloquímico em particular.

As plântulas tratadas com extratos a $4 \%$ de $E$. argentinum apresentaram raízes escurecidas e mais espessas quando comparadas ao controle. O mesmo foi constatado nas plântulas tratadas com os extratos a $4 \%$ de $O$. puberula, somando-se ao aspecto frágil e quebradiço das raízes. Nos demais tratamentos desses dois bioensaios e nos de L. divaricata e M. guianensis, a aparência da alface estava normal.

O escurecimento e a fragilidade nas raízes são danos que apontam a ação de substâncias tóxicas dos extratos. O endurecimento e escurecimento dos ápices radiculares são evidências de alterações morfológicas e anatômicas causadas por fitotoxinas (CRUZ-ORTEGA et al., 1998). Segundo Soares e Vieira (2000), reduções de tamanho e necroses em raízes de alface tratadas com extratos aquosos de espécies da família Gleicheniaceae são semelhantes ao dano provocado por detergentes naturais, como as saponinas.

A caracterização dos extratos aquosos (Quadro 2) revelou que os extratos apresentaram valores de $\mathrm{pH}$, potencial osmótico e resíduo dentro do que se considera adequado para a germinação e desenvolvimento de alface (CHOU e YOUNG, 1974; BASKIN e BASKIN, 1998; ELAKOVICH, 1999; AQÜILA, 2000). Assim, podese excluir uma interferência desses fatores nos efeitos observados sobre a alface.

As reações qualitativas de detecção de saponinas, flavonóides e taninos apresentaram alguns resultados positivos para as espécies testadas (Quadro 3). O extrato de $M$. guianensis preparado para as reações apresentouse bastante viscoso, o que pode ter interferido em alguma das técnicas de detecção empregadas. Estudos sobre a composição química das espécies-teste também apontaram a presença de metabólitos secundários que podem ser responsáveis por efeitos alelopáticos, caso tenham sido extraídos (BARALLE et al., 1972; CHAVES et al., 1988; JANUÁRIO et al., 1992; CALLE et al., 2000; ZUANAZZI et al., 2001; TANAKA et al., 2003). Entretanto, deve-se ressaltar que a mera presença desses candidatos a aleloquímicos nas espécies testadas não quer dizer que eles realmente atuem como tal (AQÜILA, 2000). Além disso, nem todos os metabólitos secundários são alelopaticamente importantes (INDERJIT e DAKSHINI, 1995).

Os resultados permitiram concluir que $E$. argentinum, L. divaricata, $M$. guianensis e O. puberula apresentam potencial alelopático. Contudo, deve-se salientar que essas espécies não apresentam indícios 
visuais da ocorrência de alelopatia a campo. Para confirmar se esse potencial se expressa em condições naturais, outras abordagens experimentais são necessárias, sendo essenciais experimentos a campo, já que nessas condições os efeitos alelopáticos podem não ser tão evidentes, caso o fenômeno ocorra realmente.

Quadro 2 - Características físico-químicas de extratos foliares aquosos de espécies nativas Table 2 -Physico-chemical characteristics of native species leaf aqueous extracts

\begin{tabular}{|c|c|c|c|c|c|c|c|}
\hline \multicolumn{2}{|c|}{ Bioensaio } & \multicolumn{2}{|c|}{ Germinação } & \multicolumn{2}{|c|}{ Crescimento } & \multirow{2}{*}{$\begin{array}{c}\mathrm{PO} \\
(\mathrm{MPa})\end{array}$} & \multirow{2}{*}{$\begin{array}{c}\text { Resíduo } \\
\left(\mathrm{mg} \cdot \mathrm{ml}^{-1}\right)\end{array}$} \\
\hline & & $\mathrm{pH}_{\mathrm{i}}$ & $\mathrm{pH}_{\mathrm{f}}$ & $\mathrm{pH}_{\mathrm{i}}$ & $\mathrm{pH}_{\mathrm{f}}$ & & \\
\hline \multirow{5}{*}{ 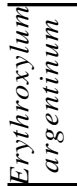 } & Controle & 5,40 & 6,00 & 5,39 & 6,00 & 0,000 & 0,000 \\
\hline & Frio $2 \%$ & 5,32 & 6,00 & 5,10 & 7,00 & $-0,025$ & 2,333 \\
\hline & Frio $4 \%$ & 5,22 & 6,00 & 5,16 & 6,00 & $-0,025$ & 3,000 \\
\hline & Quente $2 \%$ & 5,35 & 6,00 & 5,25 & 6,00 & $-0,025$ & 1,667 \\
\hline & Quente $4 \%$ & 5,16 & 7,00 & 5,26 & 7,00 & $-0,049$ & 5,000 \\
\hline \multirow{5}{*}{ 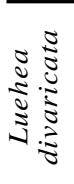 } & Controle & 5,40 & 6,00 & 5,52 & 6,00 & 0,000 & 0,000 \\
\hline & Frio $2 \%$ & 5,57 & 6,00 & 5,56 & 6,00 & $-0,025$ & 1,000 \\
\hline & Frio $4 \%$ & 5,50 & 7,00 & 5,50 & 7,00 & $-0,025$ & 2,667 \\
\hline & Quente $2 \%$ & 5,72 & 6,00 & 5,72 & 6,00 & $-0,025$ & 1,000 \\
\hline & Quente $4 \%$ & 5,58 & 7,00 & 5,59 & 7,00 & $-0,025$ & 2,667 \\
\hline \multirow{5}{*}{ 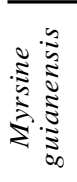 } & Controle & 5,70 & 6,00 & 5,70 & 6,00 & 0,000 & 0,000 \\
\hline & Frio $2 \%$ & 5,86 & 6,00 & 5,94 & 6,00 & $-0,025$ & 0,667 \\
\hline & Frio $4 \%$ & 5,86 & 6,00 & 5,85 & 6,00 & $-0,025$ & 2,000 \\
\hline & Quente $2 \%$ & 5,70 & 6,00 & 5,78 & 6,00 & $-0,025$ & 0,667 \\
\hline & Quente $4 \%$ & 5,57 & 7,00 & 5,78 & 7,00 & $-0,037$ & 2,333 \\
\hline \multirow{5}{*}{ 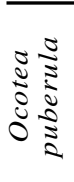 } & Controle & 5,36 & 6,00 & 5,17 & 6,00 & 0,000 & 0,000 \\
\hline & Frio $2 \%$ & 5,17 & 7,00 & 5,24 & 7,00 & $-0,025$ & 0,667 \\
\hline & Frio $4 \%$ & 5,10 & 7,00 & 5,19 & 7,00 & $-0,037$ & 4,667 \\
\hline & Quente $2 \%$ & 5,78 & 7,00 & 5,29 & 7,00 & $-0,025$ & 2,233 \\
\hline & Quente $4 \%$ & 5,19 & 7,00 & 5,00 & 7,00 & $-0,049$ & 6,000 \\
\hline
\end{tabular}

$\mathrm{H}_{\mathrm{i}}: \mathrm{pH}$ inicial; $\mathrm{pH}_{\mathrm{f}}: \mathrm{pH}$ final e PO: potencial osmótico. $H_{i}$ : initial $\mathrm{pH} ; \mathrm{pH}_{f}$ final $\mathrm{pH}$ e PO: osmotic potential.

Quadro 3 - Detecção de aleloquímicos em extratos foliares aquosos de espécies nativas *

Table 3 -Allelochemical detection in native species leaf aqueous extracts

\begin{tabular}{lccc}
\hline Espécie & Saponinas & Flavonóides & Taninos \\
\hline Erythroxylum & - & $+*$ & + \\
argentinum & & & \\
Luehea divaricata & + & - & + \\
Myrsine guianensis & - & - & + \\
Ocotea puberula & + & - & - \\
\hline
\end{tabular}

(+) presença, (-) ausência e *flavonóis.

(+) presence, (-) absence e *lavonols.

\section{AGRADECIMENTOS}

Aos biólogos Adriano Scherer e Raquel Lüdtke, pelo apoio nas coletas e no acompanhamento dos bioensaios; e ao Laboratório de Fisiologia Vegetal do Departamento de Botânica da UFRGS, pela infraestrutura cedida.

\section{REFERÊNCIAS BIBLIOGRÁFICAS}

AQÜILA, M. E. A. Efeito alelopático de Ilex paraguariensis A. St.-Hil. na germinação e crescimento inicial de Lactuca sativa L. Iheringia, Série Botânica, v. 53, p. 51-66, 2000.

AQÜILA, M. E. A.; UNGARETTI, J. A. C.; MICHELIN, A. Preliminary observation on allelopathic activity in Achyrocline satureioides (Lam.) DC. Acta

Horticulturae, v. 502, p. 383-388, 1999.

BARALLE, F. et al. Dehydroocoteine and didehydroocoteine from Ocotea puberula. Experientia, v. 28, n. 8, p. 875-876, 1972.

BASKIN, C. C.; BASKIN, J. M. Seeds: ecology, biogeography and evolution of dormancy and germination. New York: Academic Press, 1998. 666 p.

R. Árvore, Viçosa-MG, v.30, n.4, p.547-555, 2006 
BRASIL. Ministério da Agricultura e Reforma Agrária. Coordenação de Laboratório Vegetal. Regras para análise de sementes. Brasília: 1992. 365 p.

CALLE, J. et al. Alterations in the reproduction of mice induced by rapanone. Journal of Ethnopharmacology, v. 71, p. 521-525, 2000.

CHAVES, C. G. et al. Erythroxylum argentinum: assays for anti-inflammatory activity. Journal of Ethnopharmacology, v. 22, p. 117-120, 1988.

CHOU, C. H. The role of allelopathy in subtropical agroecosystems in Taiwan. In: PUTNAM, A. L.; TANG, C. S. (Ed.) The science of allelopathy. New York: John Wiley \& Sons, 1986. p. 57-73.

CHOU, C. H. \& YOUNG, C. C. Effects of osmotic concentration and $\mathrm{pH}$ on plant growth. Taiwania, v. 19, n. 2, p. 157-165, 1974.

CHUNG, I. M.; AHN, J. K. \& YUN, S. J. Assessment of allelopathic potential of barnyard grass (Echinochloa crus-gall) on rice (Oriza sativa L.) cultivars. Crop

Protection, v. 20, p. 921-928, 2001.

CRUZ-ORTEGA, R. et al. Effects of allelochemical stress produced by Sicyios deppei on seedling root ultrastructure of Phaseolus vulgaris e Curcubita ficifolia. Journal of Chemical Ecology, v. 24, n. 12, p. 2039-2057, 1998.

EINHELLIG, F. A. An integrated view of allelochemicals amid multiple stresses. In: INDERJIT; DAKSHINI, K. M. M.; FOY, C. L. (Ed.) Principles and practices in plant ecology. Boca Raton: CRC Press, 1999. p. 479-494.

ELAKOVICH, S. D. Bioassays applied to allelopathic herbaceous vascular hydrophytes. In: INDERJIT; DAKSHINI, K. M. M.; FOY, C. L. (Ed.) Principles and practices in plant ecology. Boca Raton: CRC Press, 1999. p. 45-56.

FALKENBERG, M. B.; SANTOS, R. I.; SIMÕES, C. M. O. Introdução à análise fitoquímica. In: SIMÕES, C. M. O. et al. (Ed.) Farmacognosia: da planta ao medicamento. 5. ed. Porto Alegre: Universidade Federal do Rio Grande do Sul, 2003. p. 229-245.

R. Árvore, Viçosa-MG, v.30, n.4, p.547-555, 2006
FERREIRA, A. G.; AQÜILA, M. E. A. Alelopatia: uma área emergente da ecofisiologia. Revista Brasileira de Fisiologia Vegetal, v. 12, p. 175-204, 2000. (Edição especial).

FERREIRA, A. G. et al. Allelopathy in Brazil. In: Rizvi, S. J. H.; Rizvi, V. (Ed.) Allelopathy: basic and applied aspects. London: Chapman \& Hall, 1992. p. 243-250.

INDERJIT; DAKSHINI, K. M. M. On laboratory bioassays in allelopathy. Botanical Review, v. 61, n. 1, p. $28-44,1995$.

JACOBI, U. S.; FERREIRA, A. G. Efeitos alelopáticos de Mimosa bimucronata (DC) OK. sobre espécies cultivadas. Pesquisa Agropecuária Brasileira, v. 26, n. 7, p. $935-943,1991$.

JANUÁRIO, A. H. et al. Dammarane and cycloartane triterpenoids from three Rapanea species. Phytochemistry, v. 31, n. 4, p. 1251-1253, 1992.

LABOURIAU, L. F. G. A germinação das sementes. Washington: Departamento de Assuntos Científicos e Tecnológicos da Secretaria Geral da Organização dos Estados Americanos, 1983.174 p. (Série Biologia, monografia, 24).

LOVETT, J. V.; RYUNTYU, M. Allelopathy: broadening the context. In: RIZVI, S. J. H.; RIZVI, V. (Ed.) Allelopathy: basic and applied aspects. London: Chapman \& Hall, 1992. p. 11-19.

MANLY, B.F.J. Randomization and Monte Carlo methods in biology. London: Chapman \& Hall, 1991. 399 p.

PILLAR, V. D. MULTIV, Software for multivariate exploratory analysis and randomization testing. Porto Alegre: Universidade Federal Rio Grande do Sul, 2001. 34 p.

PILLAR, V.D.; ORLÓCI, L. On randomization testing in vegetation science: multifactor comparisons of relevé groups. Journal of Vegetation Science, v. 7, p. 585-592, 1996. 
PIÑA-RODRIGUES, F. C. M.; LOPES, B. M. Potencial alelopático de Mimosa caesalpiniifolia Benth sobre sementes de Tabebuia alba (Cham.) Sandw. Floresta e Ambiente, v. 8, n. 1, p. 130-136, 2001.

REIGOSA, M. J.; SÁNCHEZ-MOREIRAS, A.; GONZÁLEZ, L. Ecophysiological approach in allelopathy. Critical Reviews in Plant Sciences, v. 18, n. 5, p. 577-608, 1999.

RICE, E. L. Allelopathy. 2 ed. New York: Academic Press, 1984. 422 p.

RIZVI, S. J. H. et al. A discipline called allelopathy. In: RIZVI, S. J. H.; RIZVI, V. (Ed.) Allelopathy: basic and applied aspects. London: Chapman \& Hall, 1992. p. 1-10.

RODRIGUES, K. C. S. Verificação da atividade alelopática de Myrciaria cuspidata Berg. (Camboim). 2002. $78 \mathrm{f}$. Dissertação (Mestrado em Botânica) Universidade Federal do Rio Grande do Sul, Porto Alegre, 2002.

RUTHERFORD, M. C.; POWRIE, L. W. Allelochemic control of biomass allocation in interacting shrub species. Journal of Chemical Ecology, v. 19, n. 5, p. 893-906, 1993.
SALISBURY, F. B.; ROSS, C. Plant physiology. Belmont: Wadsworth, 1992. 748 p.

SOARES, G. L. G.; VIEIRA, T. R. Inibição da germinação e do crescimento radicular de alface (cv. "Grand Rapids") por extratos aquosos de cinco espécies de Gleicheniaceae. Floresta e Ambiente, v. 7, n. 1, p. 180-197, 2000.

SOARES, G. L. G. et al. Potencial alelopático do extrato aquoso de folhas de algumas leguminosas arbóreas brasileiras. Floresta e Ambiente, v. 9, n. 1, p. 119-126, 2002.

TANAKA, J. C. A.; VIDOTTI, G. J.; SILVA, C. C. A new tormentic acid derivative from Luehea divaricata Mart. (Tiliaceae). Journal of Brazilian Chemical Society, v. 14, n. 3, p. 475-478, 2003.

UNGARetti, J. A. C. Atividade alelopática de Achyrocline satureioides (Lam.) DC. 2000. $199 f$. Dissertação (Mestrado em Botânica) - Universidade Federal do Rio Grande do Sul, Porto Alegre, 2000.

WHITTAKER, R. W.; FEENY, P. P. Allelochemics: chemical interactions between species. Science, v. 171, n. 3973, p. 757-769, 1971.

ZUANAZZI, J. A. S. et al. Alkaloids of Erythroxylum (Erythroxylaceae) species from Southern Brazil. Biochemical Systematics and Ecology, n. 29, p. 819-825, 2001. 